\title{
Hypoxia mediates osteocyte ORP150 expression and cell death in vitro
}

\author{
MONICA MONTESI ${ }^{1,2}$, KATHARINA JÄHN ${ }^{3}$, LYNDA BONEWALD $^{3}$, \\ SUSANNA STEA $^{1}$, BARBARA BORDINI ${ }^{1}$ and ALINA BERAUDI ${ }^{1}$
}

\begin{abstract}
${ }^{1}$ Medical Technology Laboratory, Rizzoli Orthopaedic Institute, I-40136 Bologna; ${ }^{2}$ Bioceramics and Bio-Hybrid Composites Group, Institute of Science and Technology for Ceramics, National Research Council, Faenza, I-48018 Ravenna, Italy;

${ }^{3}$ School of Dentistry, Department of Oral Biology, University of Missouri-Kansas City, Kansas City, MO 64108-2784, USA
\end{abstract}

Received January 12, 2016; Accepted June 7, 2016

DOI: $10.3892 / \mathrm{mmr} .2016 .5790$

\begin{abstract}
Skeletal unloading leads to hypoxia in the bone microenvironment, resulting in imbalanced bone remodeling that favors bone resorption. Osteocytes, the mechanosensors of bone, have been demonstrated to orchestrate bone homeostasis. Hypoxic osteocytes either undergo apoptosis or actively stimulate osteoclasts to remove bone matrix during hypoxia. Oxygen-regulated protein 150 (ORP150) is an endoplasmic reticulum-associated chaperone that has been observed to serve an important role in the cellular adaptation to hypoxia and in preventing cellular apoptosis in various tissue types. The current study hypotheses that expression of ORP150 would be increased in osteocytes under hypoxic conditions $\left(1 \% \mathrm{O}_{2}\right)$. The MLO-Y4 osteocyte cell line was cultured under normoxic or hypoxic conditions for up to $72 \mathrm{~h}$. It was demonstrated that $1 \% \mathrm{O}_{2}$ significantly induced hypoxia after $16 \mathrm{~h}$ and up to $72 \mathrm{~h}$, significantly reduced cell number at 8 and $48 \mathrm{~h}$, induced cell death at 8, 24 and $48 \mathrm{~h}$ and induced apoptosis at 16, 24 and $48 \mathrm{~h}$. Significant differences in ORP150 mRNA were observed at $72 \mathrm{~h}$, however no differences were observed in the protein expression levels. The relative increase in ORP150 mRNA observed in hypoxia, compared with normoxia, may support its cytoprotective role in oxygen-deprived conditions.
\end{abstract}

\section{Introduction}

Bone remodeling is a fundamental mechanism for removing and replacing bone during skeleton adaptation to mechanical loads. Osteocytes are the most abundant cells in bone (1-3), and they are actively involved in the orchestration of both bone-forming

Correspondence to: Dr Monica Montesi, Bioceramics and Bio-Hybrid Composites Group, Institute of Science and Technology for Ceramics, National Research Council, 64 Via Granarolo, Faenza, I-48018 Ravenna, Italy

E-mail: monica.montesi@istec.cnr.it

Key words: osteocytes, hypoxia, ORP150, apoptosis osteoblasts and bone-resorbing osteoclasts (4,5). Osteocytes implement their role by activating the signaling pathways involved in the maintenance of bone homeostasis, specifically the Wnt/ $\beta$-catenin pathway (6). This pathway has been demonstrated to be activated by mechanical loading to protect against bone loss (7) and to lead to the production of sclerostin, an inhibitor of osteoblast activity in response to unloading (8). It has been previously observed that osteocytes express receptor activator of nuclear factor $\mathrm{\kappa B}$ ligand, a pre-osteoclastogenic cytokine involved in bone resorption activation $(5,9,10)$. Osteocytes are known as the mechanosensor of bone $(11,12)$ due to their location deep within the bone matrix and their dendritic network that allows the detection of variations in the levels of strain placed upon bone $(4,13)$. Skeletal loading is fundamental in maintaining osteocyte viability (14), as demonstrated by increasing osteocyte apoptosis with disuse $(15,16)$.

Skeletal unloading, as observed in patients undergoing bed rest, results in imbalanced bone remodeling that favors bone resorption $(16,17)$. It has been suggested that the loss of bone observed during disuse is the result of osteocyte hypoxia, resulting from unloading that reduces the interstitial fluid flow and, consequentially, reduces oxygen transport $(18,19)$. It is widely regarded that disruption of the lacuno-canalicular network, which is necessary for nutrient and gaseous exchange for osteocytes, results in localized hypoxia in bone $(20,21)$.

It has been hypothesized that oxygen deprivation, due to reduced mechanical loading, may be the cause of the osteocyte apoptosis $(22,23)$ and osteoclast recruitment, in order to remove bone matrix during hypoxia (24-27). Hypoxia and oxidative stress increase the expression of different factors that mediate the adaptive responses to hypoxia/ischemia. The role of certain molecular endoplasmic reticulum (ER) chaperones has been extensively investigated, in particular regarding their functions in the quality control of proteins processed in the ER and in the regulation of ER signaling in response to stress (28).

Oxygen-regulated protein 150 (ORP150) protein $(150 \mathrm{kDa})$, a novel endoplasmic-reticulum-associated chaperone induced by hypoxia/ischemia (29), has been identified to be highly expressed in osteocytes compared with osteoblasts (30). ORP150 has been proposed to be involved in the prevention of apoptosis induced by oxygen deprivation $(31,32)$. 
The cytoprotective role of ORP150 in different cell types has been previously demonstrated and it has been hypothesized that ORP150 is required by osteocytes to survive in their reduced oxygen state into the bone matrix (33-35). The current study aimed to establish whether ORP150 levels correlated with osteocyte cell death and apoptosis under hypoxic conditions.

\section{Materials and methods}

Cell culture. The murine long bone osteocyte Y4 (MLO-Y4) cell line (supplied from University of Missouri, Kanas City, USA) was used and cultured as previously described $(36,37)$. Briefly, the cells were cultured on collagen-coated (rat tail type I collagen; BD Biosciences, Franklin Lakes, NJ, USA) plastic ware and were grown at $37^{\circ} \mathrm{C}, 5 \% \mathrm{CO}_{2}, 95 \%$ air with $\alpha$-minimal essential medium ( $\alpha$-MEM; $1 \mathrm{X}$; Invitrogen; Thermo Fisher Scientific, Inc., Waltham, MA, USA) supplemented with $2.5 \%$ fetal bovine serum (FBS) (PAA; GE Healthcare Life Sciences, Pittsburgh, PA, USA), $2.5 \%$ bovine calf serum (BCS; GE Healthcare Life Sciences, Logan, UT, USA) and 100 U/ml penicillin/streptomycin at (Invitrogen; Thermo Fisher Scientific, Inc). For the hypoxia experiments, 5,000 cells $/ \mathrm{cm}^{2}$ were seeded onto collagen-coated multi-well dishes, incubated in $\alpha$-MEM without phenol red, $2.5 \% \mathrm{FBS}+2.5 \% \mathrm{BCS}$ and $100 \mathrm{U} / \mathrm{ml}$ penicillin/streptomycin (Invitrogen; Thermo Fisher Scientific, Inc.).

To confirm the data obtained with the MLO-Y4 cells, the pre-osteoblast MC3T3-E1 cell line was additionally used. MC3T3-E1 subclone 14 was obtained from the American Type Culture Collection cell bank (Manassas, VA, USA) and was cultured as previously described (30).

Hypoxia. Time 0 was designated as $24 \mathrm{~h}$ post-seeding, which was when cell culture under normal conditions (normoxia $20 \% \mathrm{O}_{2}$ ), or hypoxic conditions (hypoxia $1 \% \mathrm{O}_{2}$ ) was initiated. Cells were cultured under these conditions for 8, 16, 24, 48 and $72 \mathrm{~h}$. For the MC3T3-E1 cells, the $16 \mathrm{~h}$ time point was not repeated, as this set of experiments was performed to confirm the result already obtained with the MLO-Y4 cell line. For hypoxic conditions, the cells were placed inside a chamber from Billups-Rothenberg, Inc. (San Diego, CA, USA), where a mixture of gas $\left(95 \% \mathrm{~N}_{2}\right.$ and $\left.5 \% \mathrm{CO}_{2}\right)$ was injected resulting in $1 \% \mathrm{O}_{2}$. The oxygen percentage was controlled by an Oxygen Analyzer/Monitor (Vascular Technology, Inc., Nashua, NH, USA).

To evaluate hypoxia of osteocytes and pre-osteoblasts, pimonidazole hydrochloride (Hypoxyprobe ${ }^{\mathrm{TM}}-1$; Chemicon; EMD Millipore, Billerica, MA, USA) (38) was used. Pimonidazole hydrochloride is a substance with low-molecular weight that binds only to cells that have an oxygen tension of $10 \mathrm{~mm} \mathrm{Hg}\left(\mathrm{pO}_{2} \sim 1,2 \%\right)$ or lower. The cultures were stained for hypoxic cells with Hypoxyprobe ${ }^{\mathrm{TM}}-1$ according to the manufacturer's protocol.

One experiment in quadruplicate was performed for each cell culture and each time point.

Cell viability and apoptosis. Osteocyte viability and total cell number were determined by trypan blue staining $(39,40)$. Three experiments in quadruplicate were performed for each cell culture and time point. The results were expressed as the number of trypan blue-positive cells, over the total number of cells. Apoptosis was assessed subsequent to 4',6-diamidino-2-phenylindole nuclear staining, counting cells exhibiting chromatin condensation or nuclear blebbing over the total number of cells (41).

Reverse transcription-quantitative polymerase chain reaction $(R T-q P C R)$. RNA isolation was performed using TRIzol reagent (Applied Biosystems; Thermo Fisher Scientific, Inc.). Total RNA (500 ng) was reverse transcribed using the High-Capacity cDNA Reverse Transcription kit (Applied Biosystems; Thermo Fisher Scientific, Inc.). Gene expression was analyzed using TaqMan Assay probes and primers for ORP150 (cat. no. Mm00491279) and $\beta 2$ macroglobulin (cat. no. Mm00437762) with Master Mix TaqMan Gene Expression reagents (Applied Biosystems; Thermo Fisher Scientific, Inc.). The cycling condition used were an initial stage of $2 \mathrm{~min}$ incubation at $50^{\circ} \mathrm{C}$ then $10 \mathrm{~min}$ at $95^{\circ} \mathrm{C}$, this was followed by 40 cycles of $95^{\circ} \mathrm{C}$ for $15 \mathrm{~min}$ and $60^{\circ} \mathrm{C}$ for $1 \mathrm{~min}$. All equipment and reagents used for the RT-qPCR were purchased from Applied Biosystems (Thermo Fisher Scientific, Inc.). The four experiments performed were conducted in triplicate; the quantification cycle $(\mathrm{Cq})$ value was determined by the default settings, using StepOne software, version 2.1 (Applied Biosystems; Thermo Fisher Scientific, Inc.). The relative expression of ORP150 in hypoxic MLO-Y4 cells was compared with the expression in MLO-Y4 cells grown for $8 \mathrm{~h}$ under normoxic conditions using the $2^{-\triangle \Delta C q}$ method (42).

Western blotting. Cells cultured under hypoxia or normoxia were lysed in radioimmunoprecipitation assay buffer complete with a proteinase inhibitor cocktail (Enzo Life Sciences, Farmingdale, NY, USA). A total of four experiments for MLO-Y4 and one for MC3T3-E1 were performed to compare the ORP150 expression in hypoxic and normoxic conditions at all different time points. A total of three different experiments were conducted in order to compare ORP150 expression in normoxic osteocytes and pre-osteoblasts. Due to the fact that the experiments made with MC3T3-E1 cells were performed to confirm the results obtained with the MLO-Y4 cells, the $16 \mathrm{~h}$ time point for this cell line was not repeated. Protein concentration was determined in each cell lysate supernatant using a DC Protein Assay kit I colorimetric assay (Bio-Rad Laborartories, Inc., Hercules, CA, USA). Equal amounts of protein $(15 \mu \mathrm{g})$ were applied and separated using $10 \%$ sodium dodecyl sulfate-polyacrylimide gel electrophoresis and transferred by electrophoresis to a nitrocellulose membrane. The membranes were blocked with $2.5 \%$ non-fat dried milk (Bio-Rad Laboratories, Inc.) in $1 \mathrm{X}$ phosphate-buffered saline at room temperature for $30 \mathrm{~min}$ and incubated with rabbit anti-ORP150 (dilution 1:1,000; cat. no. 3905-1; Epitomics, Burlingame, CA, USA) and rabbit anti- $\beta$-actin (dilution 1:1,000; cat. no. LF-PA0207; AbFrontier, Seoul, Korea) primary antibodies for $2 \mathrm{~h}$ at room temperature, with $\beta$-actin as the internal control. Horseradish peroxidase-conjugated anti-rabbit secondary antibody (dilution 1:1,000; cat. no. HAF008; R\&D Systems, Inc., Minneapolis, MN, USA) was subsequently incubated with the membranes for $1.5 \mathrm{~h}$ at room 
A

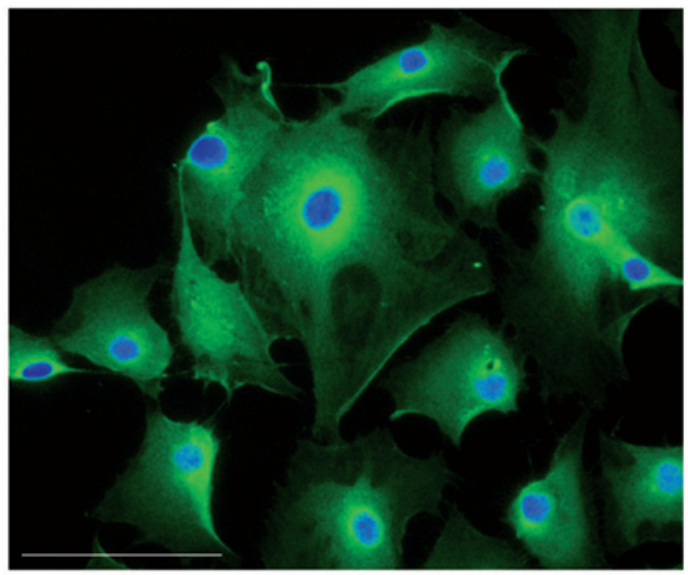

B

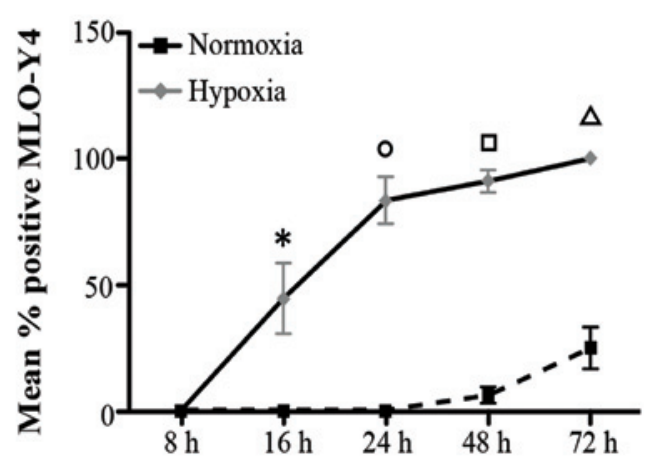

C

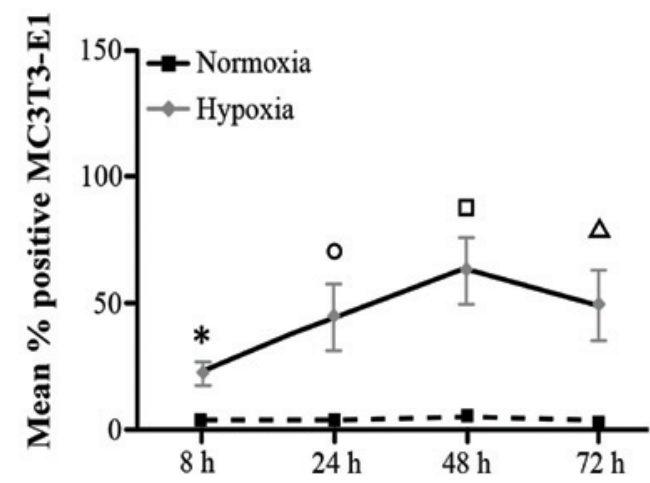

Figure 1. Effect of oxygen deprivation on MLO-Y4 and MC3T3-E1 cells detected by Hypoxyprobe staining. (A) Representative image of Hypoxyprobe staining of hypoxic MLO-Y4 at $72 \mathrm{~h}$ of treatment; pimonidazole stains hypoxic cells (green) and 4',6-diamidino-2-phenylindole stains all cell nuclei (blue). Scale bar, $25 \mu \mathrm{m}$. (B) The percentage of positive MLO-Y4 cells to Hypoxyprobe staining at different time points, in hypoxic and normoxic conditions. Cells grown in hypoxic conditions exhibit a significant increase in staining uptake, when compared with cells grown in normoxic conditions at the same time points; $\mathrm{P}=0.005$; ${ }^{\circ} \mathrm{P}=0.005 ;{ }^{\square} \mathrm{P}=0.009$; and ${ }^{\Delta} \mathrm{P}=0.007$ vs. normoxia (Mann-Whitney U test). (C) The percentage of positive MC3T3-E1 cells to Hypoxyprobe staining at different time points, in hypoxic and normoxic conditions. Cells grown in hypoxic conditions exhibited a significant increase in staining uptake, when compared with cells grown in normoxic conditions at the same time points; ${ }^{*} \mathrm{P}=0.001 ;{ }^{\circ} \mathrm{P}=0.001 ;{ }^{\square} \mathrm{P}=0.009$; and ${ }^{\Delta} \mathrm{P}=0.001$ vs. conrol (Mann-Whitney $\mathrm{U}$ test). Data are presented as the mean \pm standard error. MLO-Y4, murine long bone osteocyte Y4.

temperature. Enhanced chemiluminescent reagents (GE Healthcare Life Sciences) and films were used to visualize the protein bands and were quantified using Adobe Photoshop (Adobe Systems, Inc., San Jose, CA, USA).

Statistical analysis. Data were analyzed for normal distribution using the Kolmogorov-Smirnov test. Differences between the two oxygen conditions were assessed using Mann-Whitney U test, and differences between the experimental times were assessed using the Kruskal-Wallis test for nonparametric data. $\mathrm{P}<0.05$ was considered to indicate a statistically significant difference. Statistical analyses were performed using SPSS software, version 14.0 (SPSS, Inc., Chicago, IL, USA). Differences between data obtained by western blot analysis, comparing ORP150 expression in MC3T3-E1 and MLO-Y4 cells was assessed using Student's t-test.

\section{Results}

Induction of hypoxia. MLO-Y4 cells cultured at $1 \% \mathrm{O}_{2}$ exhibited a significantly increased level of Hypoxyprobe staining (Fig. 1A and B) compared with cells cultured in normoxic conditions at the same time points: $16,24,48$ and $72 \mathrm{~h}(\mathrm{P}=0.005$,
0.005, 0.009 and 0.007, respectively). In addition, in hypoxic conditions, the number of Hypoxyprobe-positive cells significantly increased over time (hypoxic MLO-Y4 P=0001; Kruskal Wallis test), suggesting that the cells became more sensitive to hypoxia (Fig. 1B). Conversely, the time-dependent increase of Hypoxyprobe-positive cells was not observed in normoxic conditions and only following $72 \mathrm{~h}$ exposure was a marginal increase detected. A similar trend was observed for the MC3T3-E1 cells (Fig. 1C); the number of Hypoxyprobe-positive cells was significantly different at all time points under hypoxic conditions compared with normal conditions $(8,24$, 48 and $72 \mathrm{~h} ; \mathrm{P}=0.001,0.001,0.009$ and 0.001 , respectively). In addition, a significant time-dependent increase in the number of MC3T3-E1 Hypoxyprobe-positive cells was observed under hypoxia (Kruskal Wallis test; $\mathrm{P}=0001$ ), however was not observed under normoxia (Kruskal Wallis test; $\mathrm{P}=0515$ ).

These results indicate that the two cell lines were sensitive to hypoxia under the conditions of oxygen deprivation.

Cell viability and apoptosis. Osteocyte viability, as determined by trypan blue staining, was compromised by oxygen deprivation and resulted in a significant increase in cell death at 8,24 and 48 h $(\mathrm{P}=0.049 ; \mathrm{P}=0.002 ; \mathrm{P}=0.043$, respectively), 
A

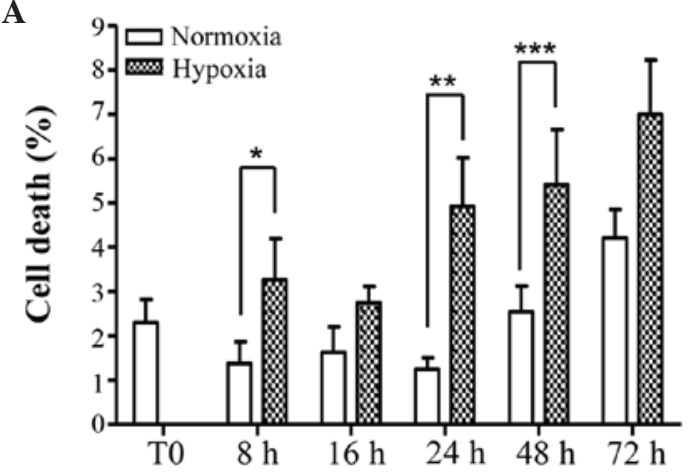

B

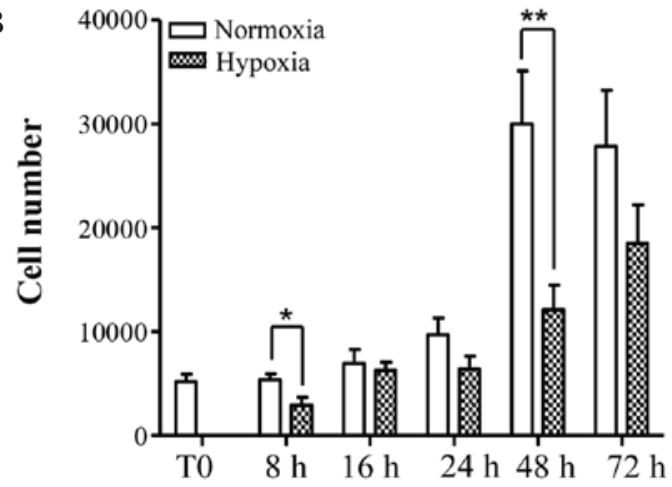

Figure 2. Cell viability and total cell number in murine long bone osteocyte $\mathrm{Y} 4$ cells under normoxic and hypoxic conditions. (A) Cell viability. A significant increase in cell death under hypoxic conditions was observed compared with normoxic conditions at the following time points: 8, 24 and $48 \mathrm{~h}$; " $\mathrm{P}=0.049$; ${ }^{* *} \mathrm{P}=0.002 ;{ }^{* * * *} \mathrm{P}=0.043$ (Mann-Whitney U test). In addition, a time-dependant statistically significant increase in cell death was observed in the hypoxic (Kruskal Wallis test; $\mathrm{P}=0.032$ ) and normoxic (Kruskal Wallis test; $\mathrm{P}=0.004$ ) groups. (B) Total cell number. Hypoxia was observed to significantly reduce the total cell number compared with normoxic conditions at 8 and $48 \mathrm{~h}:{ }^{*} \mathrm{P}=0.037 ;{ }^{* * *} \mathrm{P}=0.002$. However, a significant increase of cells over time was observed in the two culture conditions (Kruskal Wallis test; $\mathrm{P}=0.004$ and $\mathrm{P}=0000$ for hypoxia and normoxia, respectively). All values are presented as the mean \pm standard error.

however was not significant at 16 and $72 \mathrm{~h}(\mathrm{P}=0.122 ; \mathrm{P}=0.069$, respectively) (Fig. 2A). Cell counting observed an increase in total cell number over time, however, deprivation of oxygen significantly reduced total number of cells at 8 and $48 \mathrm{~h}$ compared with the same time points under normoxia (Fig. 2B). The number of apoptotic osteocytes, as determined by nuclear fragmentation, was increased by hypoxia and this increase was identified to be statistically significant at 16, 24 and $48 \mathrm{~h}$, compared with the same time points cultured under normoxia. At $72 \mathrm{~h}$, the number of apoptotic cells cultured under hypoxic conditions was reduced compared with normoxia, however this difference was identified to not be significant. The number of apoptotic cells in hypoxia at $72 \mathrm{~h}$ was additionally identified to be marginally reduced compared with the values observed at $48 \mathrm{~h}$, however this difference was not statistically significant (Fig. 3).

ORP150 expression. MLO-Y4 ORP150 mRNA expression was significantly reduced in a time-dependent manner under hypoxic and normoxic conditions. No significant differences were observed in mRNA levels under hypoxic conditions compared with normoxia apart from at $72 \mathrm{~h}$, where the difference was statistically significant with a smaller reduction under hypoxic conditions (Fig. 4). In particular, there were statistically significant differences under hypoxia identified between 72 and 16 h, 24 and 48 h ( $\mathrm{P}=0.001,0.009$ and 0.007 , respectively); similar results were obtained under normoxic conditions ( $\mathrm{P}=0.000,0.000$ and 0.012 , respectively). Western blot analysis conducted on MLO-Y4 indicated no statistically significant differences in ORP150 expression at a protein level at any time point under the same conditions of the mRNA analysis (Fig. 5). It is suggested that additional later time points would reflect the significant differences in the $72 \mathrm{~h}$ mRNA data.

Confirming the ORP150 expression data identified in MLO-Y4 cells, no differences were observed in ORP150 expression in MC3T3-E1 cells under normoxic and hypoxic conditions, similarly, there were no significant differences over time under normoxic and hypoxic conditions (data not shown). In addition, western blot analysis indicated that the expression of ORP150 was significantly

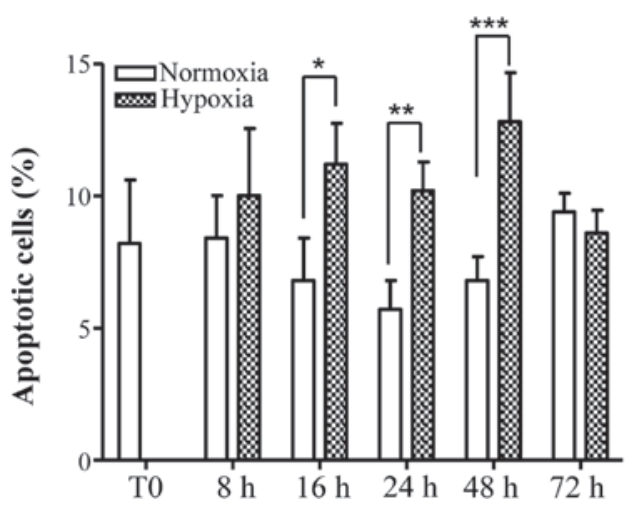

Figure 3. Evaluation of apoptosis by nuclear fragmentation. A significantly increased number of apoptotic cells in hypoxia compared with in normoxia at 16,24 and 48 h. ${ }^{*} \mathrm{P}=0.021 ;{ }^{* *} \mathrm{P}=0.006 ;{ }^{* * * *} \mathrm{P}=0.011$ (Mann-Whitney U test). All values are presented as the mean \pm standard error.

reduced in normoxic MC3T3-E1 cells (ORP150/ $\beta$-actin ratio $=0.531 \pm 0.03-$ mean \pm standard deviation- $)$ compared with normoxic MLO-Y4 cells (ORP150/ $\beta$-actin ratio $=0.845 \pm 0.06$-mean \pm standard deviation- $)$, with $\mathrm{P}=0.001$, in agreement with a previous study (30).

\section{Discussion}

The objective of the current study was to determine whether the expression of ORP150 in osteocytes is regulated in response to oxygen deprivation.

Hypoxia is a normal physiological condition for osteocytes. A concentration of approximately $5 \% \mathrm{O}_{2}$ is more likely to be physiological for osteocytes than a concentration of $20 \% \mathrm{O}_{2}$, as osteocytes are embedded deep inside the mineralized bone matrix and their nutrient availability is greatly dependent on diffusion (43-45). The actual concentration of oxygen inside of the osteocyte lacunae during skeletal unloading remains unknown. A previous study has measured $\mathrm{pO}_{2}$ values of approximately $6 \%$ in normal human bone marrow aspirates (46). On the basis of this information, $1 \% \mathrm{O}_{2}$ was selected as the hypoxic condition and $20 \% \mathrm{O}_{2}$ as the normoxic condition (representing the atmospheric 


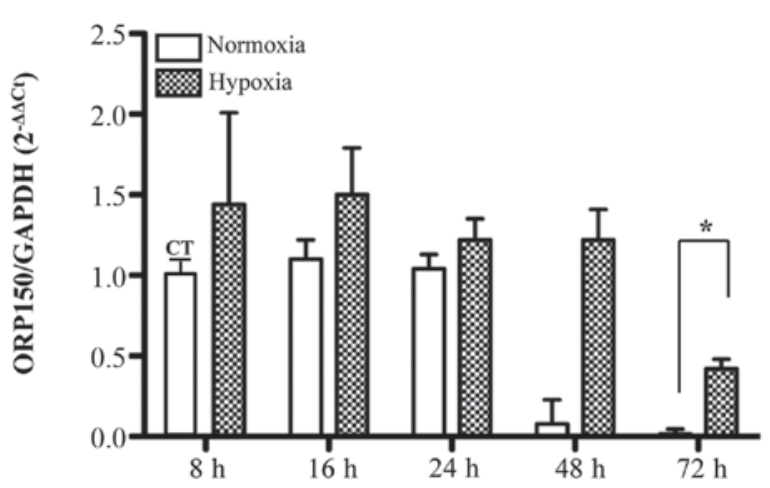

Figure 4. Murine long bone osteocyte Y4 ORP150 mRNA expression Fold-change in ORP150 expression $\left(2^{-\Delta \Delta \mathrm{Ct}}\right)$ is presented relative to expression at 8-h normoxia, used as the CT. A significant difference between hypoxia and normoxia was only observed at the 72-h time point, ${ }^{~} \mathrm{P}=0.001$ (Mann-Whitney U test). A significant time-dependent reduction in ORP150 expression was observed in hypoxic and normoxic conditions (Kruskal Wallis test; $\mathrm{P}=0001$ and $\mathrm{P}=0.000$, respectively). Values are presented as the mean \pm standard error. ORP150, oxygen-regulated protein 150; CT, control; GAPDH, glyceraldehyde 3-phosphate dehydrogenase.

oxygen levels); although it is widely accepted that a $\mathrm{pO}_{2}$ of $20 \%$ corresponds to hyperoxia (44).

On the basis of this assumption, the data of the present study indicate that $1 \% \mathrm{O}_{2}$ induces hypoxia and significantly compromises cellular viability. The results obtained additionally demonstrate that apoptosis serves a role in oxygen deprivation-mediated induction of cell death. Despite the fact that osteocytes were sensitive to hypoxia from 16 to $72 \mathrm{~h}$, as demonstrated by Hypoxyprobe staining (Fig. 1), the difference in the rate of apoptosis in hypoxia compared with normoxia, remained significant until the $48 \mathrm{~h}$ time point. Following that, the apoptotic stimuli induced by hypoxia appear to be inhibited at $72 \mathrm{~h}$, where the percentage of apoptotic cells was not identified to be significantly different in hypoxia compared with normoxia. It is hypothesized that, in the early stages, additional mechanisms of protection against oxygen deprivation-induced cell death may occur $(47,48)$.

No significant differences were observed in ORP150 mRNA levels until the $72 \mathrm{~h}$ time point, and protein levels at any time point, however, it is suggested that the protein levels may have been greater at later time points. This suggests that ORP150 mRNA expression is delayed, as based on the Hypoxyprobe results, the cells become hypoxic from $16 \mathrm{~h}$. Notably, ORP150 expression reduced over time under normoxic and hypoxic conditions. Unlike additionally cell types including Hela cells (49), neuronal cells (50-52), renal cells (53) and cardiomyocytes (54,55), in MLO-Y4 cells ORP150 does not appear to be regulated by hypoxia at early time points. Similar results were identified for the ORP150 protein expression in pre-osteoblasts grown under hypoxic conditions compared with normoxic conditions. The ORP150 protein levels were increased in MLO-Y4 osteocytes compared with MC3T3-E1 pre-osteoblasts grown under normoxic conditions. These observations are in agreement with previous studies demonstrating that low oxygen tension serves an important role in the differentiation of osteoblasts into osteocytes $(45,56)$. Guo et al $(30)$ demonstrated that a greater amount of hypoxia-associated proteins in osteocytes (such as ORP150), compared with in osteoblasts. The higher
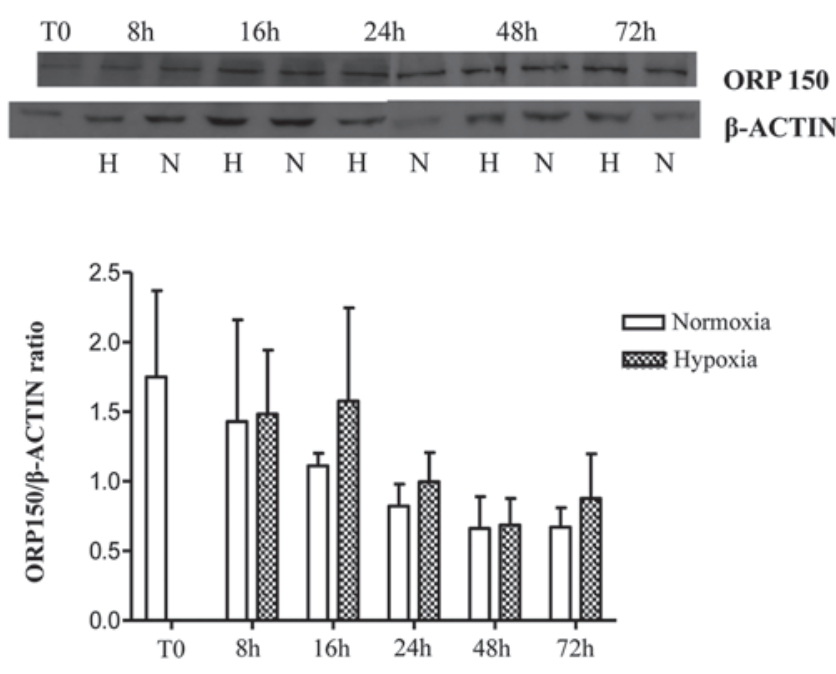

Figure 5. ORP150 protein levels in murine long bone osteocyte Y4 cells under hypoxic and normoxic conditions. ORP150 levels were measured by western blotting and the protein levels of ORP150 were normalized to $\beta$-actin. The reduction in protein expression over time was not statistically different between the hypoxic and normoxic groups. All values are presented as the mean \pm standard error. ORP150, oxygen-regulated protein 150 .

level of ORP150 protein may be a possible explanation for the capacity of osteocytes to adapt to their hypoxic environment.

In conclusion, ORP150 is commonly highly expressed in osteocytes as compared with osteoblasts, and mRNA expression is not elevated compared with the control until late stages of hypoxic culture conditions. Significant cell death and apoptosis precede the significant differences in ORP150 mRNA in hypoxia compared with normoxia. It is hypothesized that the amount of ORP150 in MLO-Y4 is sufficient to protect the cells from hypoxia up to $48 \mathrm{~h}$, however longer exposure to oxygen deprivation may lead to upregulation of ORP150 expression. After $72 \mathrm{~h}$, the significant increase in ORP150 mRNA, identified in hypoxia compared with normoxia, strongly support the hypothesis that longer exposure to hypoxia may additionally induce an increase of ORP150 protein levels. It is notable that at present the actual concentration of oxygen inside of the osteocyte lacunae remains unknown, and this should be considered a limitation. However, in order to understand the behavior of osteocytes in response to the oxygen deprivation and to increase knowledge of this complex pathway, evaluation of the hypoxic condition at early time points is scientifically valuable. It is thus important to further investigate the role of ORP150 in the apoptotic process under hypoxic conditions for longer time periods, and to block ORP150 expression, using ORP150 small interfering RNA or knockout mice, to more fully elucidate the protective role of this protein.

\section{Acknowledgements}

The authors would like to thank Dr Luca Dalle Carbonare, of the Policlinico G.B. Rossi (Verona, Italy), for providing the MLO-Y4 cell line. The authors would additionally like to thank Dr Lucia Mancini for helping with the revision of the manuscript, and Mr. Luigi Lena for the illustrations. 


\section{References}

1. Bianconi E, Piovesan A, Facchin F, Beraudi A, Casadei R, Frabetti F, Vitale L, Pelleri MC, Tassani S, Piva F, et al: An estimation of the number of cells in the human body. Ann Hum Biol 40: 463-471, 2013

2. Bonewald LF: Osteocytes as dynamic multifunctional cells. Ann N Y Acad Sci 1116: 281-290, 2007.

3. Busse B, Djonic D, Milovanovic P, Hahn M, Püschel K, Ritchie RO, Djuric M and Amling M: Decrease in the osteocyte lacunar density accompanied by hypermineralized lacunar occlusion reveals failure and delay of remodeling in aged human bone. Aging Cell 9: 1065-1075, 2010.

4. Bonewald LF: The amazing osteocyte. J Bone Miner Res 26: 229-238, 2011.

5. Nakashima T, Hayashi M, Fukunaga T, Kurata K, Oh-Hora M, Feng JQ, Bonewald LF, Kodama T, Wutz A, Wagner EF, et al: Evidence for osteocyte regulation of bone homeostasis through RANKL expression. Nat Med 17: 1231-1234, 2011.

6. Baron R and Kneissel M: WNT signaling in bone homeostasis and disease: From human mutations to treatments. Nat Med 19: 179-192, 2013

7. Javaheri B, Stern AR, Lara N, Dallas M, Zhao H, Liu Y, Bonewald LF and Johnson ML: Deletion of a single b-catenin allele in osteocytes abolishes the bone anabolic response to loading. J Bone Miner Res 29: 705-715, 2014.

8. Robling AG, Niziolek PJ, Baldridge LA, Condon KW, Allen MR, Alam I, Mantila SM, Gluhak-Heinrich J, Bellido TM, Harris SE and Turner $\mathrm{CH}$ : Mechanical stimulation of bone in vivo reduces osteocyte expression of Sost/sclerostin. J Biol Chem 283: 5866-5875, 2008.

9. Paszty C, Turner $\mathrm{CH}$ and Robinson MK: Sclerostin: A gem from the genome leads to bone-building antibodies. J Bone Miner Res 25: 1897-1904, 2010.

10. Xiong J and O'Brien CA: Osteocyte RANKL: New insights into the control of bone remodeling. J Bone Miner Res 27: 499-505, 2012.

11. Burgers TA and Williams BO: Regulation of Wnt/b-catenin signaling within and from osteocytes. Bone 54: 244-249, 2013.

12. Knothe Tate ML, Niederer $P$ and Knothe U: In vivo tracer transport through the lacunocanalicular system of rat bone in an environment devoid of mechanical loading. Bone 22: 107-117, 1998.

13. Gortazar AR, Martin-Millan M, Bravo B,Plotkin LI and Bellido T: Crosstalk between caveolin-1/extracellular signal-regulated kinase (ERK) and b-catenin survival pathways in osteocyte mechanotransduction. J Biol Chem 288: 8168-8175, 2013.

14. Knothe Tate ML: 'Whither flows the fluid in bone?' An osteocyte's perspective. J Biomech 36: 1409-1424, 2003.

15. Dufour C, Holy X and Marie PJ: Transforming growth factor-beta prevents osteoblast apoptosis induced by skeletal unloading via PI3K/Akt, Bcl-2 and phospho-Bad signaling. Am J Physiol Endocrinol Metab 294: E794-E801, 2008.

16. Jilka RL, Noble B and Weinstein RS: Osteocyte apoptosis Bone 54: 264-271, 2013

17. Bikle DD and Halloran BP: The response of bone to unloading. J Bone Miner Metab 17: 233-244, 1999.

18. Ontiveros C, Irwin R, Wiseman RW and McCabe LR: Hypoxia suppresses runx 2 independent of modeled microgravity. J Cell Physiol 200: 169-176, 2004

19. Stevens HY, Meays DR and Frangos JA: Pressure gradients and transport in the murine femur upon hindlimb suspension. Bone 39: 565-572, 2006.

20. Dodd JS, Raleigh JA and Gross TS: Osteocyte hypoxia: A novel mechanotransduction pathway. Am J Physiol 277: C598-C602, 1999.

21. Hinoi E, Ochi H, Takarada T, Nakatani E, Iezaki T, Nakajima H, Fujita H, Takahata Y,Hidano S, Kobayashi T, et al: Positive regulation of osteoclastic differentiation by growth differentiation factor 15 upregulated in osteocytic cells under hypoxia. J Bone Miner Res 27: 938-949, 2012.

22. Plotkin LI, Mathov I, Aguirre JI, Parfitt AM, Manolagas SC and Bellido T: Mechanical stimulation prevents osteocyte apoptosis: Requirement of integrins, Src kinases, and ERKs. Am J Physio Cell Physiol 289: C633-C643, 2005.

23. Wang H, Ji B, Liu XS, Nakatani E, Iezaki T, Nakajima H, Fujita H, Takahata Y,Hidano S and Kobayashi T: Osteocyte-viability-based simulations of trabecular bone loss and recovery in disuse and reloading. Biomech Model Mechanobiol 13: 153-166, 2014
24. Aguirre JI, Plotkin LI, Stewart SA, Weinstein RS, Parfitt AM, Manolagas SC and Bellido T: Osteocyte apoptosis is induced by weightlessness in mice and precedes osteoclast recruitment and bone loss. J Bone Miner Res 21: 605-615, 2006.

25. Bellido T: Osteocyte-driven bone remodeling. Calcif Tissue Int 94: 25-34, 2014.

26. Gross TS, Akeno N, Clemens TL, Komarova S, Srinivasan S, Weimer DA and Mayorov S: Selected contribution: Osteocytes upregulate HIF-1alpha in response to acute disuse and oxygen deprivation. J Appl Physiol (1985) 90: 2514-2519, 2001.

27. Noble BS, Peet N, Stevens HY, Brabbs A, Mosley JR, Reilly GC, Reeve J, Skerry TM and Lanyon LE: Mechanical loading: Biphasic osteocyte survival and targeting of osteoclasts for bone destruction in rat cortical bone. Am J Physiol Cell Physiol 284: C934-C943, 2003

28. Jung TW, Lee KT, Lee MW and Ka KH: SIRT1 attenuates palmitate-induced endoplasmic reticulum stress and insulin resistance in HepG2 cells via induction of oxygen-regulated protein 150. Biochem Biophys Res Commun 422: 229-232, 2012.

29. Kuwabara K, Matsumoto M, Ikeda J, Hori O, Ogawa S, Maeda Y, Kitagawa K, Imuta N, Kinoshita T, Stern DM, et al: Purification and characterization of a novel stress protein, the $150-\mathrm{kDa}$ oxygen-regulated protein (ORP150), from cultured rat astrocytes and its expression in ischemic mouse brain. J Biol Chem 271: 5025-5032, 1996

30. Guo D, Keightley A, Guthrie J, Veno PA, Harris SE and Bonewald LF: Identification of osteocyte-selective proteins. Proteomics 10: 3688-3698, 2010

31. Boraldi F, Annovi G, Carraro F, Naldini A, Tiozzo R, Sommer P and Quaglino D: Hypoxia influences the cellular cross-talk of human dermal fibroblasts. A proteomic approach. Biochim Biophys Acta 1774: 1402-1413, 2007.

32. Ozawa K, Kuwabara K, Tamatani M, Takatsuji K, Tsukamoto Y, Kaneda S, Yanagi H, Stern DM, Eguchi Y, Tsujimoto Y, et al: 150-kDa oxygen-regulated protein (ORP150) suppresses hypoxia-induced apoptotic cell death. J Biol Chem 274: 6397-6404, 1999

33. Kretowski R, Borzym-Kluczyk M and Cechowska-Pasko M: Hypoxia enhances the senescence effect of bortezomib-the proteasome inhibitor-on human skin fibroblasts. Biomed Res Int 2014: 196249, 2014.

34. Kretowski R, Stypulkowska A and Cechowska-Pasko M: Low-glucose medium induces ORP150 expression and exerts inhibitory effect on apoptosis and senescence of human breast MCF7 cells. Acta Biochim Pol 60: 167-173, 2013.

35. Tamatani M, Matsuyama T, Yamaguchi A, Mitsuda N, Tsukamoto Y, Taniguchi $\mathrm{M}$, Che YH, Ozawa K, Hori $\mathrm{O}$, Nishimura $\mathrm{H}$, et al: ORP150 protects against hypoxia/ischemia-induced neuronal death. Nat Med 7: 317-323, 2001.

36. Bonewald LF: Establishment and characterization of an osteocyte-like cell line, MLO-Y4. J Bone Miner Metab 17: 61-65, 1999.

37. Kato Y, Windle JJ, Koop BA, Mundy GR and Bonewald LF Establishment of an osteocyte-like cell line, MLO-Y4. J Bone Miner Res 12: 2014-2023, 1997.

38. Raleigh JA, Chou SC, Bono EL, Thrall DE and Varia MA Semiquantitative immunohistochemical analysis for hypoxia in human tumors. Int J Radiat Oncol Biol Phys 49: 569-574, 2001.

39. Ahuja SS, Zhao S, Bellido T, Plotkin LI, Jimenez F and Bonewald LF: CD40 ligand blocks apoptosis induced by tumor necrosis factor alpha, glucocorticoids, andetoposideinosteoblasts and theosteocyte-likecell line murine long bone osteocyte-Y4. Endocrinology 144: 1761-1769, 2003.

40. Jilka RL, Weinstein RS, Bellido T, Parfitt AM and Manolagas SC: Osteoblast programmed cell death (apoptosis): Modulation by growth factors and cytokines. J Bone Miner Res 13: 793-802, 1998.

41. Plotkin LI, Weinstein RS, Parfitt AM, Roberson PK, Manolagas SC and Bellido T: Prevention of osteocyte and osteoblast apoptosis by bisphosphonates and calcitonin. J Clin Invest 104: 1363-1374, 1999.

42. Livak KJ and Schmittgen TD: Analysis of relative gene expression data using real-time quantitative PCR and the 2 (-Delta Delta C (T)) Method. Methods 25: 402-408, 2001

43. Al Hadi H, Smerdon GR and Fox SW: Hyperbaric oxygen therapy suppresses osteoclast formation and bone resorption. J Orthop Res 31: 1839-1844, 2013.

44. Arnett TR: Acidosis, hypoxia and bone. Arch Biochem Biophys 503: 103-109, 2010. 
45. Hirao M, Hashimoto J, Yamasaki N, Ando W, Tsuboi H, Myoui A and Yoshikawa $\mathrm{H}$ : Oxygen tension is an important mediator of the transformation of osteoblasts to osteocytes. J Bone Miner Metab 25: 266-276, 2007.

46. Harrison JS, Rameshwar P, Chang V and Bandari P: Oxygen saturation in the bone marrow of healthy volunteers. Blood 99: 394, 2002.

47. Hou M, Liu J, Liu F, Liu K and Yu B: C1q tumor necrosis factor-related protein-3 protects mesenchymal stem cells against hypoxia- and serum deprivation-induced apoptosis through the phosphoinositide 3-kinase/Akt pathway. Int J Mol Med 33: 97-104, 2014.

48. Rouault-Pierre K, Lopez-Onieva L, Foster K, Anjos-Afonso F, Lamrissi-Garcia I, Serrano-Sanchez M, Mitter R, Ivanovic Z, de Verneuil H, Gribben J, et al: HIF-2 $\alpha$ protects human hematopoietic stem/progenitors and acute myeloid leukemic cells from apoptosis induced by endoplasmic reticulum stress. Cell Stem Cell 13: 549-563, 2013.

49. Cechowska-Pasko M, Bankowski E and Chene P: The effect of hypoxia on the expression of $150 \mathrm{kDa}$ oxygen-regulated protein (ORP 150) in HeLa cells. Cell Physiol Biochem 17: 89-96, 2006.

50. Kitano H, Nishimura $H$, Tachibana $H$, Yoshikawa $H$ and Matsuyama T: ORP150 ameliorates ischemia/reperfusion injury from middle cerebral artery occlusion in mouse brain. Brain Res 1015: 122-128, 2004.
51. Ogawa S: ORP150 (150 kDa oxygen regulated protein) suppressed neuronal cell death. Nihon Yakurigaku Zasshi 121: 43-48, 2003 (In Japanese)

52. Riezzo I, Neri M, De Stefano F, Fulcheri E, Ventura F, Pomara C, Rabozzi R, Turillazzi E and Fineschi V: The timing of perinatal hypoxia/ischemia events in term neonates: A retrospective autopsy study. HSPs, ORP-150 and COX2 are reliable markers to classify acute, perinatal events. Diagn Pathol 5: 49, 2010.

53. Arrington DD and Schnellmann RG: Targeting of the molecular chaperone oxygen-regulated protein 150 (ORP150) to mitochondria and its induction by cellular stress. Am J Physiol Cell Physiol 294: C641-C650, 2008

54. Aleshin AN, Sawa Y, Kitagawa-Sakakida S, Bando Y, Ono M, Memon IA, Tohyama M, Ogawa S and Matsuda H: $150-\mathrm{kDa}$ oxygen-regulated protein attenuates myocardial ischemia-reperfusion injury in rat heart. J Mol Cell Cardiol 38: 517-525, 2005

55. Matsusue A, Hara K, Kageura M, Kashiwagi M, Lu W, Ishigami A, Gotohda T, Tokunaga I, Nisimura A, Sugimura T and Kubo S: An autopsy case of rhabdomyolysis related to vegetamin and genetic analysis of the rhabdomyolysis-associated genes. J Forensic Leg Med 17: 46-49, 2010.

56. Dallas SL and Bonewald LF: Dynamics of the transition from osteoblast to osteocyte. Ann N Y Acad Sci 1192: 437-443, 2010. 